\title{
Sponsorship Pendidikan Kedokteran: Batasan yang Sering Terabaikan
}

\author{
Frans Santosa ${ }^{\mathrm{I}, 2}$, Muhammad Yadi Permana ${ }^{\mathrm{T}, 3}$, Mohammad Baharuddin ${ }^{\mathrm{I}, 4}$ \\ ${ }^{\mathrm{I}}$ Majelis Kehormatan Etik Kedokteran Pengurus Besar Ikatan Dokter Indonesia \\ ${ }^{2}$ Departemen Angiologi Vaskular, Fakultas Kedokteran Universitas Pembangunan Nasional "Veteran" Jakarta \\ ${ }^{3}$ Kelompok Staf Medis (KSM) Bedah RSUP Fatmawati \\ ${ }^{4}$ Departemen Obstetri dan Ginekologi, Rumah Sakit Bersalin Budi Kemuliaan, Jakarta Pusat
}

\author{
Kata Kunci \\ Gratifikasi, suap, sponsor, pendidikan, \\ kedokteran

\section{Korespondensi} \\ contact@ilmiah.id \\ Publikasi \\ (C) $2018 \mathrm{JEKI} /$ ilmiah.id

\section{DOI} \\ Io.26880/jeki.v2ir.Io \\ Tanggal masuk: 17 Februari 2018 \\ Tanggal ditelaah: 10 Maret 2018 \\ Tanggal diterima: II Maret 2018 \\ Tanggal publikasi: 19 Maret 2018
}

Abstrak Gratifikasi merupakan momok yang seringkali dikaitkan dengan tindak suap dalam korupsi. Dunia kedokteran nyatanya tidak terlepas dari isu-isu gratifikasi. Mahalnya biaya yang dibutuhkan dalam melaksanakan program Pengembangan Pendidikan Keprofesian Berkelanjutan $\left(\mathrm{P}_{2} \mathrm{~KB}\right)$ menjadi salah satu alasan pihak industri dapat masuk dan menawarkan solusi berupa sponsorship. Dalam praktiknya, kegiatan ini acap kali lupa memandang koridor etika dengan tidak mengindahkan batasan yang harus diperhatikan dengan berbagai alasan. Seorang dokter tidak diperbolehkan menerima uang tunai sebagai bentuk sponsorship tanpa terkecuali. Tidak hanya itu, terdapat regulasi lainnya yang sejatinya perlu diindahkan oleh dokter. Adanya tinjauan etik ini diharapkan mampu mengingatkan kembali atau memberikan pemahaman kepada sejawat dalam praktik sehari, hari.

Abstract Gratification is often associated with bribery in terms of corrupt practices. The world of medicine is, in fact, not completely free from gratification issues. The high cost of Continuing Medical Education (CME) program is one among many justifications for pharmaceutical companies to offer sponsorship. In daily basis, sponsorships tend to violate ethical corridor and ignore restrictions that must be considered, for various reasons. Doctor is not allowed to accept cash as form of sponsorship without any exception. There are other regulations that should be considered by doctors as well in terms of CME sponsorship. This ethical review is aimed to remind or provide understanding to fellow doctors in daily practice.

\section{PENDAHULUAN}

Maraknya kasus korupsi di Indonesia telah membuat Indonesia tercatat sebagai negara terkorup ke-13 se-Asia Pasifik dengan indeks persepsi korupsi (IPK) sebesar 37/100 menurut survei yang dilaksanakan oleh Transparency International, sebuah organisasi gerakan antikorupsi global. ${ }^{1}$ Pada praktik sehari-hari istilah korupsi begitu dekat dengan dua tindak pidana lainnya, yakni suap dan gratifikasi.

Dalam Kamus Besar Bahasa Indonesia (KBBI), gratifikasi diartikan sebagai pemberian uang hadiah kepada pegawai di luar gaji yang telah ditentukan. ${ }^{2}$ Sementara itu, suap didefinisikan sebagai pemberian sesuatu atau janji di mana diketahui atau patut diduga bahwa tujuan pemberian tersebut adalah agar seseorang dapat berbuat sesuatu yang bertentangan dengan kewenangan dan/atau kewajibannya. ${ }^{3}$ Dalam artian ini, gratifikasi dapat dianggap sebagai tindak suap apabila berhubungan dengan jabatannya di mana terdapat tendensi substansi atau kepentingan yang berlawanan dengan kewajiban atau tugasnya. ${ }^{4}$

Dalam Peraturan Menteri Kesehatan Republik Indonesia (Permenkes RI) Nomor 58 Tahun 2016 tentang Sponsorship Bagi Tenaga Kesehatan, sponsorship didefinisikan sebagai pemberian dukungan dalam segala bentuk 
bantuan dan/atau kegiatan dalam rangka peningkatan pengetahuan yang dilakukan, diorganisir atau disponsori oleh perusahaan/ industrifarmasi, alatkesehatan, alatlaboratorium kesehatan dan/atau perusahaan/industri lainnya yang dapat dipertanggungjawabkan secara transparan dan akuntabel. ${ }^{5}$

Profesi dokter dituntut untuk tidak hanya memberikan pelayanan kesehatan melainkan juga untuk terus memperbaharui ilmu agar layanan yang diberikan optimal bagi pasien. Hal inilah yang mendasari kebutuhan dokter untuk ikutserta dalam berbagai simposium kedokteran. Besarnya biaya yang dibutuhkan untuk sebuah simposium kemudian terselesaikan dengan hadirnya berbagai sponsor dari berbagai pihak, seperti perusahaan farmasi dan lain-lain. Lantas, bagaimana kaitan sponsorship ini dengan tindak gratifikasi?

\section{HASIL DAN PEMBAHASAN}

\section{Besarnya Biaya Program Pengembangan Pendidikan Keprofesian Berkelanjutan (P2KB)}

Menjadi seorang dokter bukanlah sebuah keputusan mudah layaknya jawaban anak ketika ditanyai mengenai cita-citanya. Dokter merupakan sebuah profesi di mana di dalamnya dibutuhkan sebuah dedikasi untuk terus menuntut ilmu bahkan setelah lulus dari bangku kuliah. Hal ini bukan isapan jempol semata. Pendidikan berkelanjutan yang terangkai sebagai Program Pengembangan Pendidikan Keprofesian Berkelanjutan (P2KB) atau Continuing Professional Development (CPD) merupakan suatu hal yang wajib diikuti oleh dokter di Indonesia. 6 Salah satu cara IDI untuk memotivasi hal tersebut adalah melalui regulasi Satuan Kredit Profesi (SKP), di mana seorang dokter wajib mengumpulkan 250 SKP dalam 5 tahun dengan proporsi kegiatan pembelajaran sebesar 20-30\% dari target SKP atau mencapai 10-15 SKP per tahun. ${ }^{7}$ SKP pembelajaran ini diperoleh dengan mengikuti kegiatan simposium kedokteran. Akan tetapi, hal ini kemudian menjadi momok mengingat biaya registrasi dan akomodasi sebuah simposium kedokteran tidaklah sedikit. Belum lagi, seringnya simposium kedokteran dilaksanakan di ibu kota dan kota-kota besar lainnya sehingga dokter-dokter di area yang jauh dari pusat kota tersebut membutuhkan biaya lebih dalam hal transportasi.

Besarnya biaya yang harus dikeluarkan kemudian membuat sebuah peluang bagi industri untuk memberikan sponsorship kepada dokter melalui pembiayaan biaya registrasi, akomodasi, transportasi, bahkan hingga menggelar simposium kedokteran yang gratis diikuti oleh seluruh dokter di Indonesia. Hal ini kemudian menempatkan dokter pada posisi dilema etik mengingat kekhawatiran terkait batas antara sponsorship dan gratifikasi yang dinilai masih cukup abu-abu.

\section{Tinjauan Hukum Gratifikasi}

Menurut UU Nomor 31 Tahun 1999 tentang Tindak Pidana Korupsi (Tipikor) pasal 13, setiap orang yang memberi hadiah atau janji kepada pegawai negeri dengan mengingat kekuasaan atau wewenang yang melekat pada jabatan atau kedudukannya, atau oleh pemberi hadiah atau janji dianggap melekat pada jabatan atau kedudukan tersebut, akan dipidana dengan pidana penjara paling lama 3 (tiga) tahun dan/ atau denda paling banyak 150.000.000,00 (seratus lima puluh juta rupiah). ${ }^{8}$ Adapun peraturan ini kemudian diperbaharui melalui UU Nomor 20 Tahun 2001 tentang Perubahan Atas UU Tipikor. Dalam UU tersebut, pada penjelasan pasal $12 \mathrm{~B}$, tertulis bahwa yang dimaksud tindak gratifikasi adalah pemberian dalam arti luas, yakni meliputi pemberian uang, barang, rabat (discount), komisi, pinjaman tanpa bunga, tiket perjalanan, fasilitas penginapan, perjalanan wisata, pengobatan cuma-cuma, dan fasilitas lainnya. Gratifikasi tersebut baik yang diterima di dalam negeri maupun di luar negeri dan yang dilakukan dengan menggunakan sarana elektronik atau tanpa sarana elektronik yang berhubungan dengan jabatan atau kewenangan. ${ }^{9}$

Dalam Peraturan Menteri Kesehatan RI Nomor 14 Tahun 2014 tentang Pengendalian Gratifikasi di Lingkungan Kementerian Kesehatan, gratifikasi dikategorikan menjadi dua, yakni gratifikasi yang dianggap suap dan 
gratifikasi yang tidak dianggap suap. Gratifikasi yang dianggap suap dijelaskan sebagai gratifikasi yang diterima oleh aparatur yang berhubungan dengan jabatan dan berlawanan dengan kewajiban dan tugas penerima. Sementara itu sebaliknya, gratifikasi yang tidak dianggap suap dijelaskan sebagai gratifikasi yang diterima oleh aparatur yang tidak berhubungan dengan jabatan dan tidak berlawanan dengan kewajiban dan tugas penerima. ${ }^{10}$

Gratifikasi yang dianggap suap meliputi namun tidak terbatas pada penerimaan marketing fee atau imbalan yang bersifat transaksional yang terkait dengan pemasaran suatu produk, cashback yang diterima instansi yang digunakan untuk kepentingan pribadi, gratifikasi yang terkait dengan pengadaan barang dan jasa, pelayanan publik, atau proses lainnya, serta sponsorship yang terkait dengan pemasaran atau penelitian suatu produk. ${ }^{10}$

Seorang dokter yang bekerja di instansi pemerintah, seperti RSUD, merupakan aparatur negara yang oleh karenanya aturan bahwa aparatur negara bebas gratifikasi juga berlaku.

\section{Tinjauan Hukum Sponsorship}

Dalam Permenkes No. 58 Tahun 2016 tentang Sponsorship bagi Tenaga Kesehatan pasal 4, tercantum bahwa sponsorship yang diberikan kepada tenaga kesehatan harus memenuhi 7 prinsip sebagai berikut:

1. tidak mempengaruhi independensi dalam pemberian pelayanan kesehatan;

2. tidak dalam bentuk uang atau setara uang;

3. tidak diberikan secara langsung kepada individu;

4. sesuai dengan bidang keahlian;

5. diberikan secara terbuka;

6. dikelola secara akuntabel dan transparan

Pemberian sponsorship tersebut menurut

Permenkes harus melalui pihak instansi. Akan tetapi pada pelaksanaannya, di beberapa instansi muncul konflik kepentingan terkait praktik pemberian sponsorship $\mathrm{P} 2 \mathrm{~KB}$ melalui instansi. Sempat ditemukan bahwa adanya konflik kepentingan antara pihak manajemen dengan dokter menimbulkan kurang tepat sasarannya sponsorship P2KB tersebut dengan alasan pemerataan hak dokter oleh manajemen rumah sakit.

Adapun honorarium pada sponsorship dalam rangka $\mathrm{P} 2 \mathrm{~KB}$ memiliki aturan tersendiri yang tercantum pada Permenkes No. 58 Tahun 2016 pasal 4. Seorang dokter dapat menerima honor berupa uang tunai bila yang bersangkutan menjadi pembicara dan/atau moderator pada acara P2KB. ${ }^{5}$

\section{Tinjauan Etik}

Pertanyaan kemudian timbul terhadap bagaimana regulasi terkait gratifikasi dan sponsorhip bagi dokter yang berpraktik di instansi bukan milik pemerintah (swasta). Mengingat bahwa seorang dokter wajib menjunjung tinggi, menghayati dan mengamalkan sumpah dokter, serta tidak boleh dipengaruhi oleh sesuatu yang mengakibatkan hilangnya kebebasan dan kemandirian profesi, seluruh dokter di Indonesia dituntut untuk bersikap transparan dan bebas gratifikasi terkait tawaran sponsor dari industri farmasi maupun tindakan insentif serupa lainnya. ${ }^{11}$

Adapun kontroversi terhadap isi dari Permenkes No. 14 Tahun 2014 pasal 6 ayat (2) poin $\mathrm{k}$ - yang menyatakan bahwa kompensasi atau penghasilan atas profesi yang dilaksanakan pada saat jam kerja, dan mendapatkan ijin tertulis dari atasan langsung dan atau pihak lain yang berwenang tergolong ke dalam gratifikasi yang tidak dianggap suap tidak terkait kedinasan - turut menambah kesimpangsiuran informasi terkait cakupan gratifikasi. ${ }^{10}$

Terkait sponsorship dalam rangka P2KB, pada 11 Juni 2007, Pengurus Besar Ikatan Dokter Indonesia dan Pengurus Pusat GP Farmasi Indonesia menyepakati nota kesepahaman tentang "Kesepakatan Bersama Etika Promosi Obat", sebagai berikut: ${ }^{12}$

a. seorang dokter dalam melakukan pekerjaan kedokterannya tidak boleh dipengaruhi oleh sesuatu yang mengakibatkan hilangnya kebebasan dan kemandirian profesi $(\mathrm{Hal}$ ini sesuai dengan Kode Etik Kedokteran Indonesia Pasal 3). Kaitannya dengan promosi obat adalah dokter dilarang mengarahkan pasien untuk membeli obat tertentu karena dokter yang bersangkutan 
telah menerima komisi dari perusahaan farmasi tertentu.

b. Dukungan apapun yang diberikan perusahaan farmasi kepada seorang dokter untuk menghadiri pertemuan ilmiah tidak boleh disyaratkan/dikaitkan dengan kewajiban untuk mempromosikan atau meresepkan suatu produk.

c. Perusahaan farmasi boleh memberikan sponsor kepada seorang dokter secara individual dalam rangka pendidikan kedokteran berkelanjutan, yaitu hanya untuk biaya registrasi, akomodasi dan transportasi dari dan ke tempat acara pendidikan kedokteran berkelanjutan.

d. Perusahaan farmasi dilarang memberikan honorarium dan atau uang saku kepada seorang dokter untuk menghadiri pendidikan kedokteran berkelanjutan, kecuali dokter tersebut berkedudukan sebagai pembicara atau menjadi moderator.

e. Dalam hal pemberian donasi kepada profesi kedokteran, perusahaan farmasi tidak boleh menawarkan hadiah/penghargaan, insentif, donasi, finansial dalam bentuk lain sejenis, yang dikaitkan dengan penulisan resep atau anjuran penggunaan obat/produk perusahaan tertentu.

Sejatinya, dalam KODEKI tahun 2012 telah diatur bahwa dokter dapat menerima bantuan dari pihak sponsor untuk keperluan uang registrasi, transportasi dan akomodasi simposium kedokteran dalam jangka pelaksanaan dan $\mathrm{H}-1$ dan $\mathrm{H}+1$ pelaksaan kegiatan secara individu tanpa membawa anggota keluarga. Yang perlu diperhatikan adalah bahwa pemberian sponsor tersebut tidak boleh dalam bentuk uang tunai. ${ }^{11}$

Apabila dalam kondisi mendesak, seorang dokter dapat menerima sponsor dalam bentuk uang dengan transfer melalui bank. Hal ini dapat dipertimbangkan sepanjang masih dalam konteks sponsor untuk keperluan uang registrasi, transportasi dan akomodasi simposium kedokteran dalam jangka pelaksanaan dan $\mathrm{H}-1$ dan $\mathrm{H}+1$ pelaksaan kegiatan atas nama pribadi tanpa membawa anggota keluarga, mengingat metode transfer bank menyediakan bukti hitam di atas putih yang dapat dipertanggungjawabkan kemudian.

Bila pada praktiknya terdapat imbal jasa yang harus diberikan kepada pemberi sponsor berupa periklanan suatu produk, dokter harus memperhatikan batasan-batasan seorang dokter dalam beriklan.

Sebuah kajian terhadap dokter beriklan telah dilakukan pada tahun 2017 dengan kesimpulan bahwa dalam beriklan terdapat batas-batas yang harus dokter perhatikan, antara lain: ${ }^{13}$

1. Dokter tidak boleh mengiklankan produkproduk dengan klaim kesehatan dan kecantikan dengan membawa gelar dan atribut kedokteran tanpa terkecuali.

2. Konten iklan tidak boleh mengandung unsur memuji diri, produk, ataupun layanan komersial yang dapat menjatuhkan marwah profesi kedokteran.

Batasan tersebut berlaku dalam segala hal dan kondisi, tanpa memandang metode periklanan yang digunakan. Begitu pula pada lips-ad atau promosi via oral seperti pada mimbar simposium, kedua rambu yang disebutkan sebelumnya tetap harus diperhatikan.

\section{Solusi Baru terhadap Biaya P2KB}

Abad ke-21 di mana teknologi komunikasi berkembang pesat ternyata mampu menawarkan sebuah solusi. Dengan memanfaatkan sambungan internet, P2KB dapat dilaksanakan dengan lebih efisien dan hemat biaya. Kini, sudah mulai cukup bermunculan e-symposium yang diadakan oleh berbagai instansi. Melalui e-symposium dokter dapat ikut serta menyaksikan dan mengikuti sesi tanya jawab secara online di daerah kediaman masing-masing sehingga menghemat biaya akomodasi dan transportasi.

Meskipun demikian, kemudahan yang ditawarkan ini memiliki sisi tricky yang perlu diberi perhatian. Perkembangan sambungan internet berbanding lurus dengan perkembangan media sosial. Angka pengguna media sosial setiap tahunnya pun terus bertambah. Dokter-dokter juga tidak sedikit yang telah memanfaatkan sosial media untuk berbagai kepentingan. Pada pelaksanaannya, terdapat koridor etika dokter di media sosial dan dunia maya yang telah dikaji dan disimpulkan 
bahwa keterlibatan konten yang membutuhkan batasan dan sifatnya bukan untuk publik tidak boleh disebarluaskan dalam media sosial dengan tingkat privasi dan keamanan yang kurang. Bila memang diperlukan, dokter dapat mengelola dua akun terpisah di mana satu akun dengan tujuan edukasi kedokteran dan akun lainnya sebagai akun pribadi untuk menyalurkan ekspresi. ${ }^{14}$

\section{KESIMPULAN}

Dokter sebagai praktisi perseorangan yang berbasis pada asas kemanusiaan, wajib menolak pemberian segala bentuk apapun bila dikaitkan atau diduga dikaitkan dengan kapasitas profesionalnya dalam meresepkan obat.

Dalam KODEKI tahun 2012 dinyatakan, bahwa seorang dokter diperbolehkan menerima bantuan dari pihak sponsor tetapi bukan dalam bentuk uang tunai melainkan bentuk langsung seperti pengurusan registrasi atas nama dokter tersebut yang kemudian ditembuskan ke atasan/pemimpin langsung atau organisasi profesi. Penerimaan bantuan dari pihak sponsor tersebut harus sepengetahuan institusi atau profesi terutama karena berkaitan dengan izin meninggalkan tugas. Seorang dokter harus bersikap transparan terkait sponsorship ini.

Selain itu bantuan transportasi dan akomodasi simposium kedokteran dalam jangka pelaksanaan dan $\mathrm{H}-1$ dan $\mathrm{H}+1$ pelaksaan kegiatan juga boleh diterima dengan atas nama pribadi tanpa membawa anggota keluarga. Seorang dokter tidak boleh melakukan imbal jasa berupa mengiklankan produk dengan klaim kesehatan dan kecantikan sekalipun secara oral di mimbar simposium semata.

Solusi lain yang dapat membantu pelaksanaan P2KB adalah digitalisasi pelaksanaan simposium ke dunia maya dalam bentuk e-symposium dengan biaya yang lebih terjangkau. Pelaksanaan simposium jarak jauh via internet tersebut perlu didorong agar lebih cepat berkembang di Indonesa.

Terlepas dari segala batasan atas praktik sponsorship dalam rangka $\mathrm{P} 2 \mathrm{~KB}$, seorang dokter tidak perlu merasa terbebani. Sepanjang dokter tersebut bersikap jujur dan berada dalam koridor dengan mematuhi rambu-rambu yang telah disebutkan di atas, dokter tidak perlu khawatir akan munculnya masalah. Dengan demikian diharapkan P2KB bagi dokter dapat terlaksana dengan baik sesuai dengan kaidah etika dan norma hukum sehingga sebagai hasil akhirnya, pelayanan kesehatan yang terbaik bagi pasien dan masyarakat dapat terwujud.

\section{KONFLIK KEPENTINGAN}

Tidak ada konflik kepentingan.

\section{REFERENSI}

1. Transparency Intenational. Corruption perceptions index 2016 [internet]. 2016 [diakses 2018 Feb 28]. Diunduh dari: https://www. transparency.org/news/feature/corruption_ perceptions_index_2016

2. Kementerian Pendidikan dan Kebudayaan. Arti kata gratifikasi - Kamus Besar Bahasa Indonesia (KBBI) Online [internet]. 2017 [diakses 2018 Feb 28]. Diunduh dari: http://kbbi.web.id/gratifikasi

3. Undang-Undang Republik Indonesia nomor 11 tahun 1980 tentang tindak pidana suap. 1980.

4. Kusumasari D. Perbedaan antara suap dan gratifikasi [internet]. 2011 [diakses $2018 \mathrm{Feb}$ 28]. Diunduh dari: http://www.hukumonline. com/klinik/detail/cl3369/perbedaan-antarasuap-dengan-gratifikasi

5. Peraturan Menteri Kesehatan nomor 58 tahun 2016 tentang sponsorship bagi tenaga kesehatan. 2016.

6. Ikatan Dokter Indonesia. Pedoman pelaksanaan program pengembangan pendidikan keprofesian berkelanjutan (P2KB). Edisi ke-3. 2017. p.11.

7. Ikatan Dokter Indonesia. Panduan verifikasi kegiatan P2KB dokter tahun 2017. 2017. p.13.

8. Undang-Undang Republik Indonesia nomor 31 tahun 1999 tentang pemberantasan tindak pidana korupsi. 1999. 
9. Undang-Undang Republik Indonesia nomor 20 tahun 2001 tentang perubahan atas undang-undang nomor 31 tahun 1999 tentang pemberantasan tindak pidana korupsi. 2001.

10. Peraturan Menteri Kesehatan Republik Indonesia nomor 14 tahun 2014 tentang pengendalian gratifikasi di lingkungan Kementerian Kesehatan. 2014.

11. Majelis Kehormatan Etik Kedokteran Indonesia. Kode etik kedokteran tahun 2012. Jakarta: Ikatan Dokter Indonesia; 2012.

12. Pengurus Besar Ikatan Dokter Indonesia. Kesepakatan bersama etika promosi obat. 2013. Diunduh dari: http://www.idionline.org/wpcontent/uploads/2013/05/MOU-GP-Farmasa. pdf

13. Prawiroharjo P, Meilia PDI. Dokter beriklan: Sebuah tinjauan menurut kode etik kedokteran Indonesia (KODEKI) tahun 2012. Jurnal Etika Kedokteran Indonesia. 2017;1(1);13. doi: 10.26880/ jeki.v1i1.4

14. Prawiroharjo P, Librianty N. Tinjauan etika penggunaan media sosial oleh dokter. Jurnal Etika Kedokteran Indonesia. 2017;1(1):31. doi: 10.26880/jeki.v1i1.7 